AperTO - Archivio Istituzionale Open Access dell'Università di Torino

\title{
Catalytically self-sufficient cytochromes P450 for green production of fine chemicals
}

\section{This is a pre print version of the following article:}

Original Citation:

Availability:

This version is available http://hdl.handle.net/2318/1668177

since 2019-03-12T14:21:38Z

Published version:

DOI:10.1007/s12210-016-0581-z

Terms of use:

Open Access

Anyone can freely access the full text of works made available as "Open Access". Works made available under a Creative Commons license can be used according to the terms and conditions of said license. Use of all other works requires consent of the right holder (author or publisher) if not exempted from copyright protection by the applicable law. 


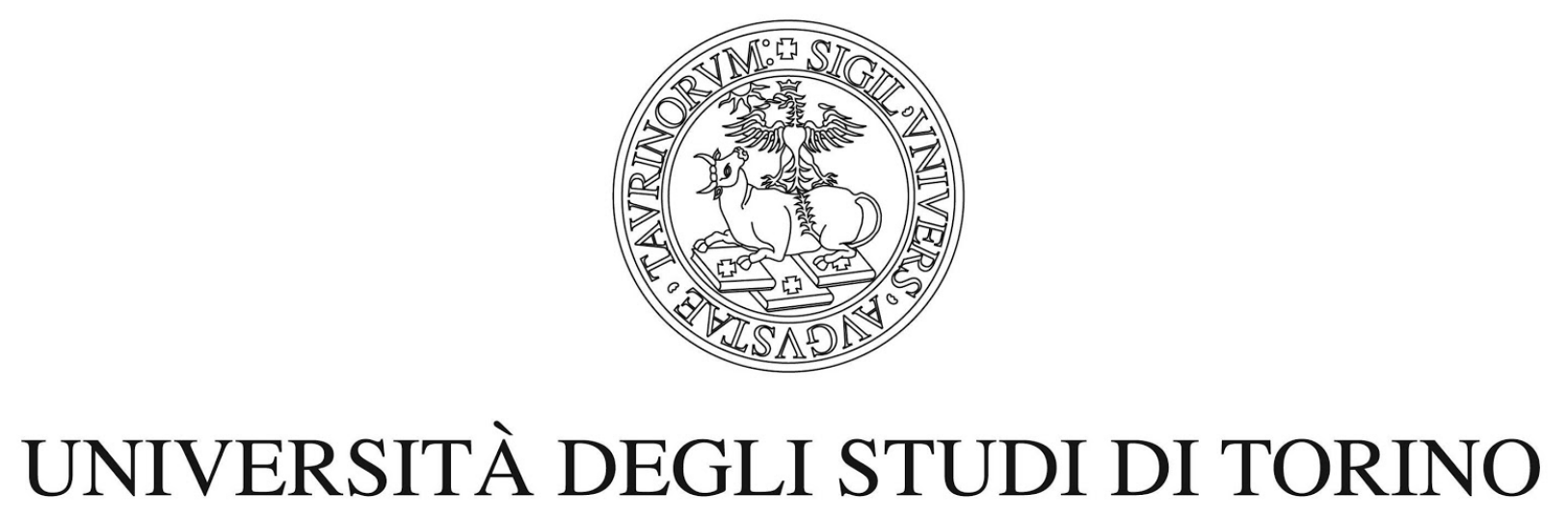

This is the accepted version of the following article:

[Ciaramella, A., Minerdi, D., Gilardi, G. Catalytically self-sufficient cytochromes P450 for green production of fine chemicals, Rendiconti Lincei, July 2017, Volume 28, Supplement 1, pp 169-181],

which has been published in final form at [https://link.springer.com/article/10.1007/s12210-016-0581-z] 


\title{
Catalytically self-sufficient cytochromes P450 for green production of fine chemicals
}

\author{
${ }^{1}$ Alberto Ciaramella, Daniela Minerdi and Gianfranco Gilardi* \\ Department of Life Sciences and Systems Biology, University of Torino, \\ Via Accademia Albertina 13, 10123 Torino, Italy
}

Running title: Catalytically self-sufficient cytochromes P450

Keywords: Cytochromes P450, heme reactivity, monoxygenases, self-sufficient enzymes, biocatalysis, drugs synthesis

Corresponding author: Gianfranco Gilardi, Department of Life Sciences and Systems Biology, University of Torino, Via Accademia Albertina 13, 10123 Torino

Tel: +39-011-6704593; Fax: +39-011-6704643; Email addess: gianfranco.gilardi@unito.it

\section{ABSTRACT}

This review covers our current knowledge on catalytically self-sufficient cytochromes P450.

These enzymes present all the advantages of the regio- and stereo-selectivity of typical P450s combined with the fact that, due to the natural fusion with their reductases, their application in biocatalysis does not need the addition of other proteins: only $\mathrm{NAD}(\mathrm{P}) \mathrm{H}$ and substrate are needed to trigger catalysis.

To this date only few catalytically self-sufficient P450s have been isolated from bacteria, fungi and plants. Their low number does not detract from their importance, as the reactions they catalyse and the turnover numbers of which they are capable (in some cases higher than $15,000 \mathrm{~s}^{-1}$ ) makes them highly relevant to the

1 This contribution is the written, peer-reviewed version of a paper presented by a participant to the Conference "'Concepts in catalysis : from heterogeneous to homogeneous and enzymatic catalysis" held at Accademia Nazionale dei Lincei in Rome on February 25-26, 2016. 
chemical and pharmaceutical industry.

These enzymes will be covered in this review, together with their specific reactions relevant to the field of biocatalysis.

Keyword: monoxygenases; P450; heme proteins; biocatalysts; 


\section{INTRODUCTION.}

Cytochromes P450 (P450s) are heme-thiolate enzymes representing a large superfamily of proteins widely diffused in organisms from all kingdoms of life including viruses (Table 1). They are characterized by an absorbance peak at $450 \mathrm{~nm}$ appearing when the heme is reduced and complexed with carbon monoxide (CO). They can perform a wide variety of regio- and stereo-selective reactions on a large range of substrates making them an attractive target as biocatalysts for green chemistry applications.

Tab. 1. Number of named P450 sequences to date (Nelson 2009).

\begin{tabular}{|l|r|r|}
\hline \multicolumn{1}{|c|}{ ORIGIN } & \multicolumn{2}{c|}{ NUMBER OF NAMED } \\
\multicolumn{1}{|r|}{ Insects } & 6,119 & \\
\hline Animals & 10,477 \\
\hline Other vertebrates & 1,344 & \\
\hline \multicolumn{1}{|c|}{ Non-insect invertebrates } & 1,348 & \\
\hline Plants & & 13,978 \\
\hline Fungi & & 7,873 \\
\hline Protozoa & & 602 \\
\hline Bacteria & & 2,156 \\
\hline Archaea & & 52 \\
\hline Viruses & & 28 \\
\hline TOTAL & & $\mathbf{3 5 , 1 6 6}$ \\
\hline
\end{tabular}

This review will concentrate on plant, fungal and bacterial catalytically self-sufficient P450s that are most relevant to chemical catalysis applications. We will also consider protein engineering approaches, by random mutagenesis on residues of the catalytic site as well as by rational design and fusion of different P450 catalytic domains with various reductase domains to obtain catalytically self-sufficient chimeric enzymes. Here the gene of $\mathrm{P} 450$ redox partner and of the heme domain from different $\mathrm{P} 450 \mathrm{~s}$ are fused together in a single gene producing a single polypeptide chain capable of independent catalysis, enhancing the biotechnological potential of the natural enzymes (Gilardi et al. 2002, Sadeghi et al. 2013).

\section{P450 REACTIVITY.}


P450s act as terminal monooxygenases performing reactions involving the transfer of one atom from molecular oxygen to $\mathrm{X}-\mathrm{H}$ bonds, where $\mathrm{X}$ may be the $-\mathrm{C},-\mathrm{N}$ or $\mathrm{S}$ of a substrate, with the concomitant reduction of the remaining oxygen atom to water (Garfinkel 1958). The reaction uses the reducing power of $\mathrm{NAD}(\mathrm{P}) \mathrm{H}$ according to the scheme:

\section{Reaction 1:}

$$
\mathrm{RH}+\mathrm{O}_{2}+\mathrm{NAD}(\mathrm{P}) \mathrm{H}+\mathrm{H}^{+} \rightarrow \mathrm{ROH}+\mathrm{H}_{2} \mathrm{O}+\mathrm{NAD}(\mathrm{P})^{+}
$$

Hydroxylation is the most common reaction carried out by P450s, but a wide range of other possibilities also exist, as shown in Figure 1. These include the formation of dicarboxylic acids from alkanes, epoxidations, N, S- and O-dealkylations, dehalogenations, peroxidations and N-oxide reductions (Guengerich and Munro 2013).

A

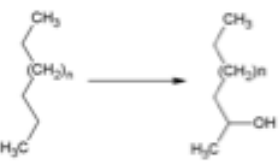

Hydroxylation of fatty acid

B

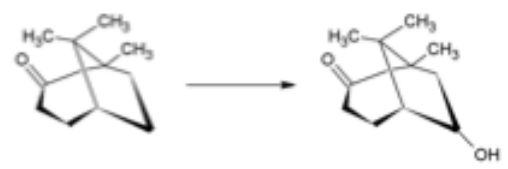

Camphor Hydroxylation

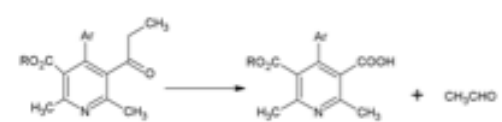

Oxidative ester cleavage

D

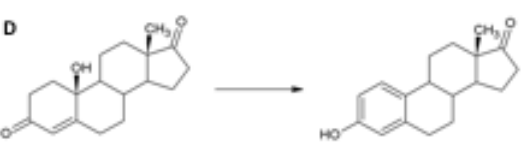

Aromatization of the A ring of a steroid
E

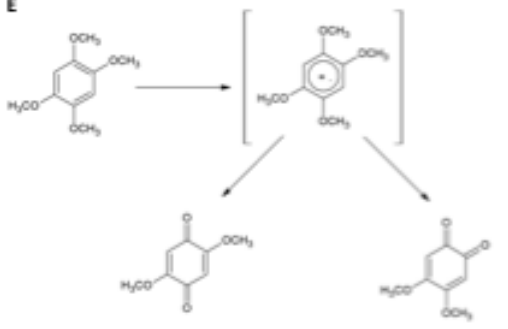

Electron oxidation of an aryl group
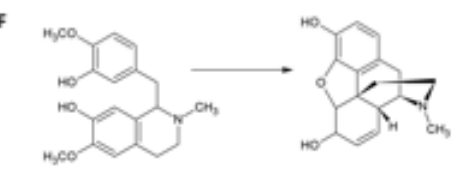

Oxidative ring coupling

G

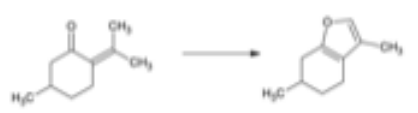

Ring formation

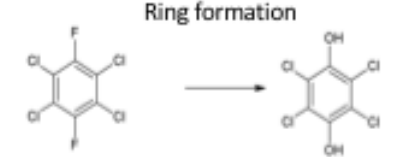

Aromatic dehalogenation via ipso attack

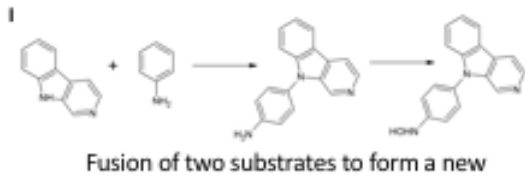

substrate

J

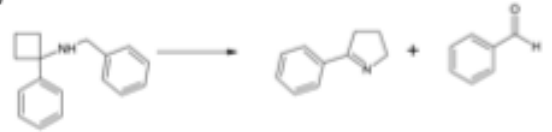

Ring expansion

к

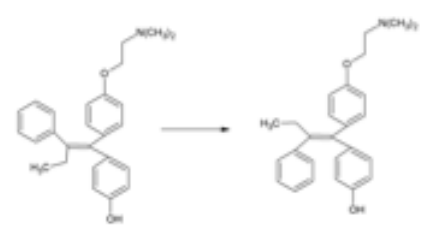

Isomerization via (abortive) oxidation
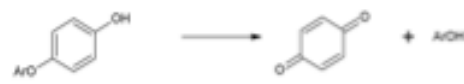

Dearylation

FIGURE 1. Known reactions described for P450s. (Adapted from Isin and Guengerich 2007)

Moreover, these reactions can be performed on a wide spectrum of substrates owing to the highly flexible substrate recognition sequences (SRS) present on their 3D structure (Gotoh 1992). Figure 2 shows the localisation of the SRS in the P450cam (CYP101A1). 


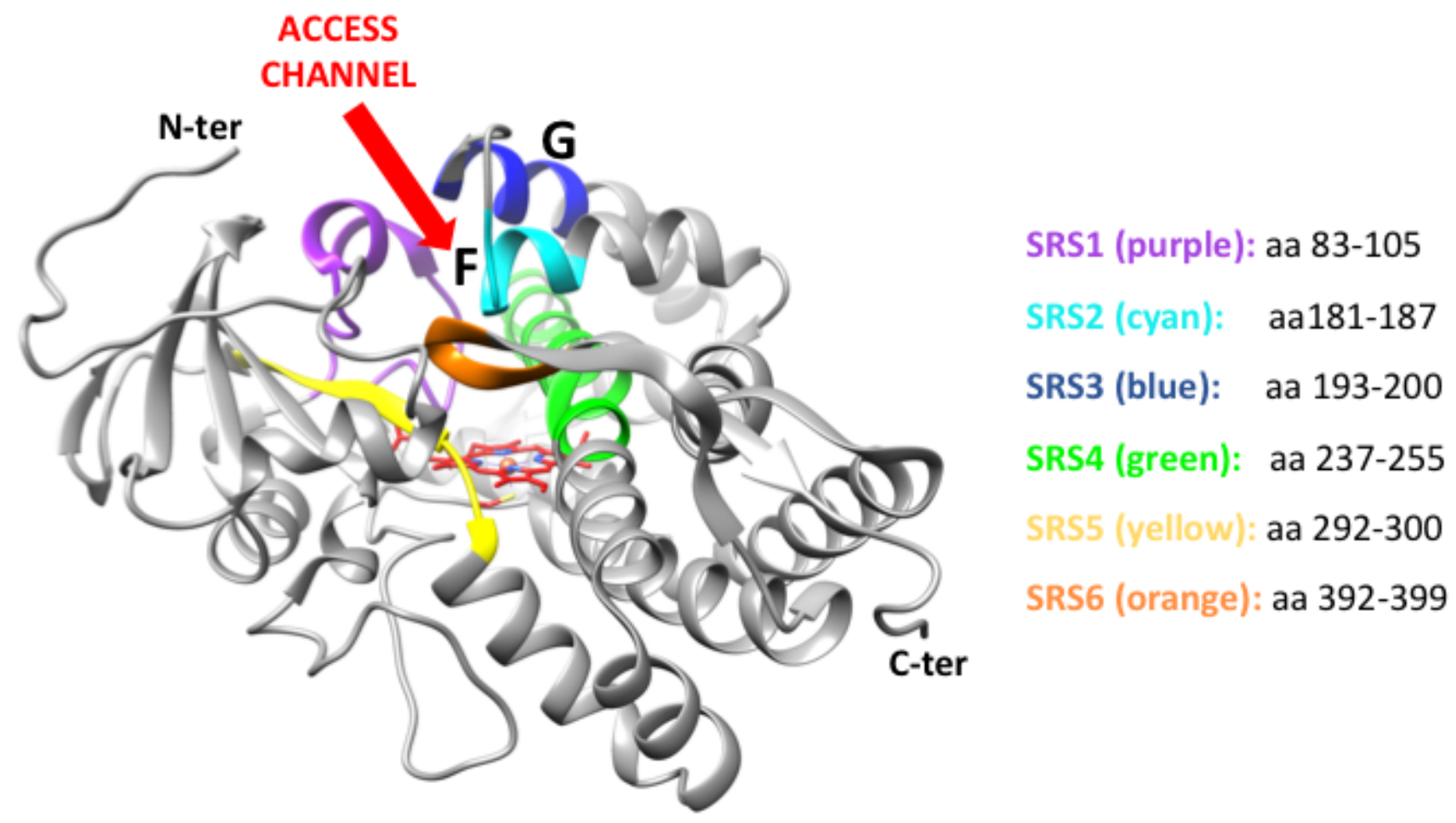

FIGURE 2. SRSs regions in the P450cam (CYP101A) X-ray structure (PDB 2CPP) (Poulos et al. 1987).

The wide range of reactions listed above, combined with the large spectrum of substrates covered by different natural and engineered P450s, makes them a good target for the production of fine chemicals by environmentally sustainable means (Valetti and Gilardi 2004, Gilardi and Di Nardo 2016).

In all cases the P450 reactivity must be sustained by an electron supply that ultimately is represented by $\mathrm{NAD}(\mathrm{P}) \mathrm{H}$. This normally provides the electrons through a reductase partner or a domain that in turns binds and delivers two electrons to the P450 heme. The mode of electron supply forms the basis for a classification of these enzymes as illustrated in the following section.

\section{P450 CLASSIFICATION BASED ON ELECTRON TRANSFER PARTNERS.}

Redox protein partners or reductases are key for providing the electrons required to support the P450 catalytic cycle allowing to deliver the two required electrons one at the time to the different intermediates in the P450 catalytic cycle (Gilardi and Di Nardo 2016, Sevrioukova et al. 1999). For some P450s, its reductase is one or more separate proteins made of one or more domains. In some cases the reductase domain is fused with the P450 domain in one polypeptide chain. There, the enzyme is self-sufficient, in that only NADPH addition is needed to trigger catalysis without the need of adding separate proteins. Only very rarely P450s have been found to achieve the reductive 
activation of oxygen without involving any redox partner (Toritsuka et al. 1997 and Stundl et al. 1998).

In early days, P450 had been classified in only two classes, class I and class II, but to this date, many more P450s have been discovered with a variety of electron deliver systems, leading to a new classification that comprises ten different classes (Hannemann et al. 2007), from class I to class X. Figure 3 systematically shows all classes of P450s, but here in the text we will only describe classes VII to X that correspond to the self-sufficient systems.

Class VII P450s are bacterial, soluble and cytosolic multi-domain enzymes. A single polypeptide chain comprises a heme containing P450 domain at N-terminus as well as a FMN containing reductase domain at the $\mathrm{C}$-terminus. The reductase domain has been found to be closely related to the phthalate oxidase reductase (PFOR) (De Mot and Parret 2002). Class VII P450 are considered self-sufficient enzymes, as they are able to perform reactions in the presence of the only electron donor, without the necessity of a redox partner (Hannemann et al. 2007). This class is well represented by the CYP116B subfamily, that they take part in reactions involving substrates such as thiocarbamate pesticides relevant from a bioremediation point of view (Warman et al. 2012). Substrates as alkanes, aromatic compounds and terpenes were also found to be involved in different oxidation reactions involving these enzymes (Yin et al. 2014).

Class VIII encompasses cytosolic self-sufficient P450 enzymes, both prokaryotic and eukaryotic. Here a single polypeptide chain contains the heme domain at the $\mathrm{N}$-terminus while a reductase domain homologous to the eukaryotic cytochrome P450 reductase (CPR), containing both FAD and FMN subdomains is present at the C-terminus.

This class is represented by CYP102A1 from Bacillus megaterium an important model P450 enzyme that will be described in details later. 


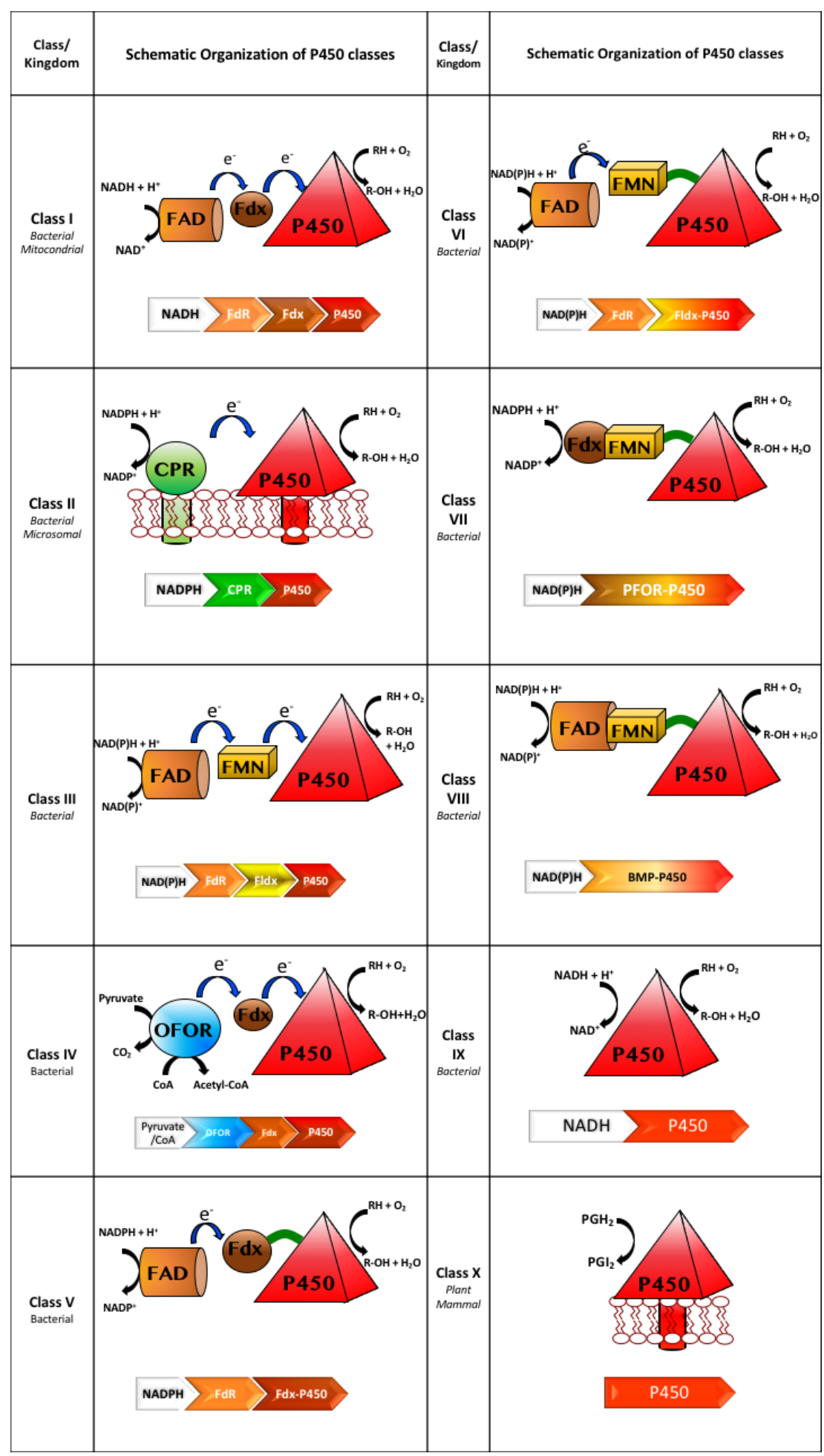

FIGURE 3. Classification of P450s on the basis of their electron transfer partners or requirements. Abbreviation: Fdx (iron-sulfur-cluster: [2Fe-2S], [3Fe-4S], [4Fe-4S], [3Fe-4S]/[4Fe-4S] type); FdR/FAD, Ferredoxin reductase (FAD); CPR, cytochrome P450 reductase (FAD, FMN); Fldx, Flavodoxin (FMN); OFOR, 2-oxoacid: ferredoxin oxidoreductase (thiamin pyrophosphate, [4Fe4S] cluster); PFOR, phthatate-family oxygenase reductase (FMN, [2Fe-2S] cluster). 
Also the self-sufficient P450 from ascomycete fungus Fusarium oxysporum belongs to class VIII: CYP505A1 (P450 foxy). It catalyses C8-C18 fatty acids hydroxylation at $\omega-1-\omega-3$ as the bacterial counterpart BM3 (Nakayama et al. 1996) as described later.

Class IX comprises nitric oxide reductase from Fusarium oxysporum CYP55, also known as P450nor (EC 1.7.99.7), that is a particular cytochrome involved in the denitrification process. Only a few additional members of this class have been characterized (Zhang et al. 2001 and Kudo et al. 1996). These enzymes do not have monooxygenase activity, but they show a unique electron transfer chain system. P450nor uses NADH directly as an electron donor without the need of a redox partner to reduce two molecules of nitric oxide (NO) to nitrous oxide $\left(\mathrm{N}_{2} \mathrm{O}\right)$. This is to protect the fungus from NO inhibition, especially when dioxygen becomes limiting (Daiber et al. 2005). This is a unique reductive process in $\mathrm{P} 450$ reactivity. Some real technological application regarding this class of enzymes has recently been proposed (Garny et al. 2016).

Class X comprises a P450-only system similar to class IX but rather particular features. It comprises the CYP74 family. CYP74A (AOS) is an allene synthase as well as CYP74B/C that is a fatty acid hydroperoxide lyase (Shibata et al. 1995). CYP74(DES) (Itoh and Howe 2001), that is crucial in the oxidative metabolism of polyunsaturated fatty acid hydroperoxides, that are converted into different oxylipins with important roles in plant growth (Hou et al. 2016).

The catalytic features in biosynthesis and the function of these enzymes are shared in mammal P450s prostacyclin synthase and thromboxane synthase, that are involved in the arachidonic acid cascade.

The peculiar feature of these enzymes resides in the fact that they do not require $\mathrm{O}_{2}$ or $\mathrm{NAD}(\mathrm{P}) \mathrm{H}$ for their reactions, but rather they use acyl hydroperoxide that is the oxygen donor as well as the substrate (Lau et al. 1993), forming new carbon oxygen bonds.

\section{CATALYTICALLY SELF-SUFFICIENT P450s.}

Catalytically self-sufficient cytochromes P450 are included in classes VII to X. Class VII and VIII P450s show a reductase naturally fused to the P450 catalytic domain, therefore for these enzymes to function and perform catalysis is only necessary to add $\mathrm{NAD}(\mathrm{P}) \mathrm{H}$ and substrate, without the need to add other electron transfer proteins. This represents a distinct advantage from the catalytic and biotechnological point of view. To date only very few self-sufficient P450s have been found, mainly deriving in bacteria, fungi and plants. Nevertheless, inspired by the protein architecture of these self-sufficient P450 systems, different kinds of artificial fusion proteins have been constructed 
with protein engineering approaches (Sadeghi and Gilardi 2013). Here we report the most relevant systems for each of these groups.

\subsection{Bacterial enzymes}

\section{CYP102A1 from Bacillus megaterium}

The most intensively studied bacterial P450 enzyme is CYP102A1 (Miura and Fulco 1974), known as P450 BM3 isolated from the soil bacterium Bacillus megaterium. This self-sufficient $\mathrm{P} 450$ is soluble and is composed of a eukaryotic-like P450 reductase containing a FAD and FMN subdomains fused to a P450 domain. The solubility is a great advantage and it makes P450 BM3 a very good model system for electron transfer studies. It was one of the first bacterial P450 enzymes to be crystallized both in its open, substratefree, and closed, substrate-bound, forms. Due to its high homology to the class II human drug-metabolizing enzymes, for many years this enzyme has been used as a paralog for the eukaryotic enzymes.

It is able to hydroxylate a range of fatty acids at $\omega-1, \omega-2$ and $\omega-3$ positions, displaying the highest monooxygenase activity of any P450 system investigated to date, that is in the region of $17000 \mathrm{~s}^{-1}$ for the substrate arachidonate (Munro et al. 2002). Its catalytic activities, combined with mutagenesis studies, has produced enzymes suitable for drug metabolite production such as hydroxylation of diclofenac, ibuprofen and tolbutamide (Tsotsou et al. 2012, Sideri et al. 2013), as well as in the development of process-scale approaches (Di Nardo and Gilardi 2012), methane oxidation, and more generally has produced mutants with improved selectivity to allow the synthesis of fine chemicals (Whitehouse et al. 2012). Some of these mutants have also been characterized in details by X-ray crystallography (Di Nardo et al. 2016). Moreover, its FAD and FMN containing reductase (BMR) has been used to drive catalysis in artificial fusion systems (Sadeghi and Gilardi 2013, Astuti et al. 2004).

\section{The 116B subfamily}

CYP116B2, also referred as P450RhF, was the first enzyme in the 116B subfamily to be expressed and purified by Roberts et al. (2003). From the N- to the C-terminus, its reductase shows three distinct functional parts: a FMN-binding domain, a NADPH-binding domain and a [2Fe-2S] ferredoxin domain. Considering the general fold, the ferredoxin domain is supposed to be between the heme domain and the FMN-domain. Therefore, the electron transport is supposed to go from the primary electron donor $(\mathrm{NAD}(\mathrm{P}) \mathrm{H})$ via the $\mathrm{FMN}$ and the $[2 \mathrm{Fe}-2 \mathrm{~S}]$ cluster of the reductase domain to the P450 domain. 
In the same family is CYP116B3 that catalyses the $o$-dealkylation of 7-ethoxycoumarin producing 7- hydroxycoumarin. In the presence of NADPH, it is also capable of hydroxylation towards aromatic hydrocarbons, naphthalene, indene, acenaphthene, toluene, fluorene, $m$-xylene and ethyl benzene (Liu et al. 2006).

Recently, our laboratory has isolated a novel 116B cytochrome from Acinetobacter radioresistens growing on alkanes as a sole energy source. It can be used in the hydroxylation of long (C24-C36) and medium-chain (C14, C16) alkanes (Minerdi et al. 2015). At present, further analysis of P450 domain are undergoing. Early experiments on the purified P450 domain are present in this paper for the first time and indicate the presence of the typical P450 spectroscopic features (figure 4). Moreover, a crystallization screening of the heme domain is being carried out.

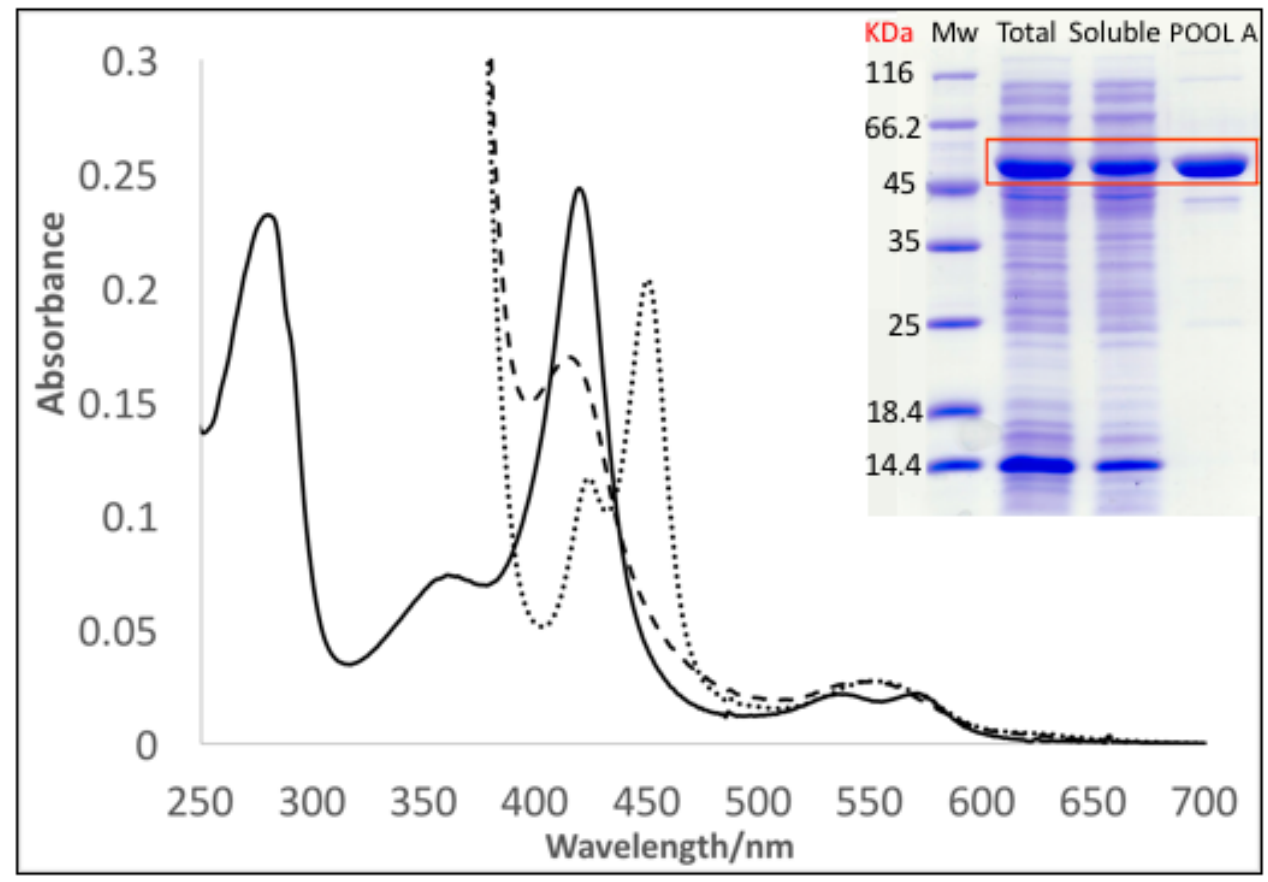

FIGURE 4. UV/Vis absorption spectra for purified 116B5 heme domain showing the purified oxidized enzyme (solid line), the dithionite-reduced enzyme (dashed line), and the reduced CObound complex (dotted line). The CO-bound reduced difference spectrum and the SDS gel before and after the purification are shown in the inset.

\section{Other bacterial P450s}

Very recently two novel CYP102 from the bacterium Ktedonobacter racemifer have been characterized as Krac0936 and Krac9955 (Munday et al. 2016). Krac0936 mainly hydroxylates long saturated fatty acids at the $\omega-1$ and $\omega-2$ positions and cis,cis-9,12-octadecadienoic, as well as pentadecanoic acids. Krac9955 is able to oxidize the tridecanoic, tetradecanoic and pentadecanoic 
acid oxidation at the $\omega-4, \omega-5$ and $\omega-6$ positions, together with lower activity towards unsaturated fatty acids.

Other closely related enzymes are CYP102A2 and A3 from Bacillus subtilis, (Gustafsson et al. 2004) A5 (Chowdhary et al. 2007) from Bacillus Cereus and A7 (Dietrich et al. 2008) from Bacillus nicheliformis.

CYP102D1 from Streptomyces avermitilis has been reported to be a class VIII self-sufficient enzyme. It catalyses fatty acid hydroxylation showing similar substrate preference profiles and kinetic properties with the CYP102 family (Choi et al. 2012).

\subsection{Fungal enzymes}

To date all fungal catalyically self-sufficient P450s have been found in the species Fusarium, in particular Fusarium oxysporum and Fusarium verticillioides.

\subsubsection{P450s from Fusarium oxysporum.}

\section{CYP55: nitric oxide reductase.}

Nitrogen fixation or nitrification carried out by microorganisms represents the main step in the nitrogen cycle, a fundamental process necessary to support life and key to maintaining nitrogen homeostasis on Earth. The inverse process, called denitrification, has been well characterized in bacteria where the process occurs under anaerobic conditions and it involves four reducing steps involving the following enzymes (Shoun et al. 2012):

Reaction 2, nitrate reductase (dNar):

Reaction 3, nitrite reductase (dNir):

Reaction 4, nitric oxide reductase (Nor):

Reaction 5, nitrous oxide reductase (Nos):

$$
\begin{aligned}
& \mathrm{NO}_{3}{ }^{-}+2 \mathrm{H}^{+} \rightarrow \mathrm{NO}_{2}{ }^{-}+\mathrm{H}_{2} \mathrm{O} \\
& \mathrm{NO}_{2}{ }^{-}+2 \mathrm{H}^{+} \rightarrow \mathrm{NO}+\mathrm{H}_{2} \mathrm{O} \\
& 2 \mathrm{NO}+2 \mathrm{H}^{+} \rightarrow \mathrm{N}_{2} \mathrm{O}+\mathrm{H}_{2} \mathrm{O} \\
& \mathrm{N}_{2} \mathrm{O}+2 \mathrm{H}^{+} \rightarrow \mathrm{N}_{2}+\mathrm{H}_{2} \mathrm{O}
\end{aligned}
$$

Denitrification also occurs in fungi where the best studied system is the one of the ascomycete Fusarium oxysporum. Here the nitric oxide reductase activity is carried out by the cytochrome P450nor (Nakahara et al. 1993; Takaya and Shoun, 2000). 
from the soil fungus Fusarium oxysporum as a heme enzyme with a lipoxygenase activity and typical P450 spectral properties (Shoun et al. 1983). P450nor is widely diffused, mainly across the subdivision of ascomycotina (Shoun et al. 2012). It is present both in the mitochondria and in the cytoplasm of fungal cells and its molecular weight has been reported to range from 42 to $46 \mathrm{KDa}$ (Nakahara et al. 1993; Usuda et al. 1995; Zhang et al. 2001). CYP55 is able to use NADH as a direct electrons donor, according to a process that is very unusual in that the two electrons from NADH are transferred here simultaneously to the heme as a hydride ion. The reaction is divided into three steps. First substrate (NO) binds to ferric $\left(\mathrm{Fe}^{3+}\right) \mathrm{P} 450$ nor to form a ferric-NO complex (reaction 6), then the $\mathrm{Fe}^{3+}$-NO is reduced with $\mathrm{NAD}(\mathrm{P}) \mathrm{H}$ to form the specific heme intermediate ( $\mathrm{I}_{\text {heme}}$ ) that shows a Soret peak at $444 \mathrm{~nm}$ (reaction 7), and finally it interacts with the second $\mathrm{NO}$ to form $\mathrm{N}_{2} \mathrm{O}$ (reaction 8).

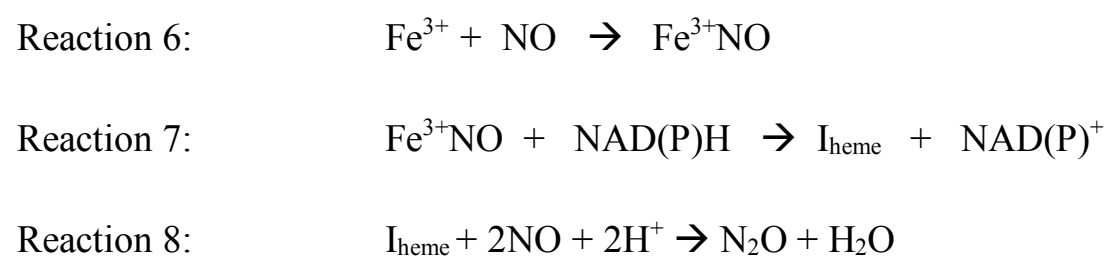

The chemical nature of the $\mathrm{I}_{\text {heme }}$ intermediate seems to be ferric-hydroxylamine radical complex (Daiber et al. 2002). Direct electron transfer from NADH to the heme of P450nor was demonstrated by the resolution of the crystal structure of P450nor complexed with the NADH-analogue nicotinic acid adenine dinucleotide, NAAD (Oshima et al. 2004). The structure of the P450nor-NAAD complex showed a conformational change upon binding of NAAD since the entrance gate of the heme distal pocket is closed. Glu71, Arg64 and Asp88 form a salt bridge network to stabilize the protein structure (Umemura et al. 2004; Su et al. 2004). Nitric oxide reductase is employed for the quantification in solution of nitric oxide (Garny et al. 2014), biosensores development and research tools for the study of the biological roles of this important cellsignalling molecule (Mur et al. 2006).

The use of NO scavengers, toxic chemical compounds that could mask the NO function (Turpaev et al. 2004), impaired the current in vitro research analysis of the biological role of nitric oxide. To overcome this limit, the use of an enzymatic system of NO reduction could be a valid option. A good candidate is represented by $\mathrm{P} 450$ nor since it is monomeric, has a single domain and accept electrons directly from its cofactor NADH/NADPH. Garny and colleagues (2016) developed a novel, dual enzyme system coimmobilizing on carboxyl-functionalized hyper-porous microspheres, the P450nor from Aspergillus oryzae and Bacillus megaterium glucose dehydrogenase with enzyme activity maintenance of $158 \%$ for P450nor and $104 \%$ for glucose dehydrogenase. The system is capable not only of continuously reduce NO but also to recycle the NADH cofactor through the action of glucose and glucose dehydrogenase. The NOR system reduces NO in a concentration-dependent manner and is able to maintain the cell viability when cytotoxic 
concentration of nitric oxide are used.

\section{CYP505: fatty acid hydroxylase.}

Another self-sufficient cytochrome $\mathrm{P} 450$ isolated from $F$. oxysporum is represented by $\mathrm{P} 450$ foxy belonging to CYP505 family (Nakayama et al. 1996; Kitazume et al. 2000, 2002). This is a membrane bound enzyme composed of a $\mathrm{N}$-terminal heme domain naturally fused to a carboxy-terminal reductase domain in a single polypeptide. Phylogenetic analysis of the heme domain provided evidence that it is the eukaryotic counterpart of the bacterial BM3. Pfoxy catalyzes the sub-terminal $\omega-1$ to $\omega-3$ carbons fatty acids hydroxylation. Redox equivalents given by NADPH go to the FAD and FMN cofactors present in the reductase domain and then to the heme. Since the heme and reductase domains are naturally fused, the turnover number of Pfoxy is one hundred-fold higher than the one of conventional class II P450s, with which shares the electron transfer mechanism (Kitazume et al. 2002).

The hydroxylation on specific carbon atoms of aliphatic compound is important in industrial chemical synthesis. In fact, omega fatty acids terminally oxidized are useful for the synthesis of industrial compounds with pharmaceutical and commercial interests such as potential anticancer drugs, cosmetic intermediates, adhesives and bioplastics (Durairaj et al. 2015). Enzymatic hydroxylation of specific C-H bonds is an interesting solution since a specific carbon atoms are hydroxylated. Self-sufficient cytochromes P450 are ideal candidates for this kind of application since they do not depend upon P450 reductase, furthermore their high turn-over number allow their application in high-throughput catalytic systems development. Recombinant fungal Pfoxy expressed in Escherichia coli cells convert saturated fatty acids with a chain length from $\mathrm{C} 7$ to $\mathrm{C} 16$ that are present in waste lard and vegetable oils originating from recycling industry to their $\omega-1$ to $\omega-3$ hydroxy derivatives (Kitazume et al. 2008).

\subsubsection{P450s from Fusarium verticillioides.}

\section{CYP505B1.}

Another member of class VIII, called CYP505B1 (Fum6p), has been identified in the filamentous ascomycete Fusarium verticillioides showing the highest aminoacid sequence identity with P450foxy (Seo et al. 2001). F. verticillioides is a maize pathogen that produces the mycotoxin fumonisin that can accumulate in infected maize and cause fatal animal diseases and human esophageal cancer (Sydenham et al. 1990). CYP505 is organized in the same way as P450foxy involved in the mycotoxin fumonisin biosynthesis (Seo et al., 2001). Fumonisin is a linear 20-carbon backbone, that has a polyketide origin, substituted at various positions with an amine, one to three hydroxyl, two methyl, and two tricarboxylic acid groups. Gene 
disruption analysis revealed that FUM6 gene is required for fumonisin production and Northern blot analysis revealed that its expression is correlated with fumonisin production (Proctor et al. 2003).

\subsection{Plant enzymes.}

\section{CYP74 family.}

Plant CYP74 is a family of self-sufficient cytochromes P450 belonging to class $\mathrm{X}$ with electron transfer properties very different from the typical P450s. They utilize an acyl hydroperoxide of the substrate both as the oxygen donor and as the substrate in which the new carbon-oxygen bonds are formed. Therefore, they do not require $\mathrm{O}_{2}$ or a NADPH-dependent cytochrome $\mathrm{P} 450$ reductase or $\mathrm{NAD}(\mathrm{P}) \mathrm{H}$ (Itoh and Howe 2001; Lau et al. 1993; Shibata et al. 1995) and have low CO affinity. To date class X P450s have not been found to be present in mammals.

The CYP74 family comprises the allene oxide synthase (CYP74A), fatty acid hydroperoxide lyase (CYP74B, CYP74C) and divinyl ether synthase (CYP74D). CYP74A, B, C and D are present in the chloroplast membranes where they are key enzymes of the plant lipoxygenase pathway (Froehlich et al. 2001).

Fatty acid hydroperoxide lyase is an enzyme that cleaves hydroperoxides of polyunsaturated fatty acids to form short chain aldehydes and $\omega$-oxoacid. It is a component of the oxylipin pathway and holds a central role in eliciting plant defence (Psylinakis et al. 2001). Allene oxide synthase is involved in the metabolic pathway that produces the plant growth regulator jasmonic acid from unsaturated free fatty acids (Vick and Zimmerman, 1984). Divinyl ether synthase converts hydroperoxides into the divinyl ethers (Grechkin and Hamberg, 1996).

\subsection{Artificial P450-reductase fusion systems produced by protein engineering}

The requirement of the addition of a redox partner protein to sustain P450 enzymatic catalysis is considered a bottle neck in biocatalysis due to the necessity of different components in solution, with a possible loss in efficiency and higher costs. This has motivated many works in which P450 enzymes of biotechnological interest that are not natural fusion with their reductase have been engineered to produce artificial multi-domain systems. In this way the enzyme and a reductase of choice are fused at genetic level to produce a single polypeptide chain. As a result, the engineered protein comprises two domains: the catalytic P450 domain and the reductase electron transfer domain requiring only addition of $\mathrm{NAD}(\mathrm{P}) \mathrm{H}$ and substrate to perform catalysis. Many such constructs have been reported to date in the literature, where their advantages in terms of the 
improvement of their catalytic properties, coupling efficiency and possibly solubility are reported in comparison with their separate parent enzymes (Sadeghi and Gilardi, 2013). In some cases, human P450 fusion proteins have been shown to be useful tools for the study of drug metabolism, with consequences of drug-drug interactions and the activation of carcinogens.

The first fusion protein reported in literature in 1987 is the rat CYP1A1/rat NADPH CYP reductase system (Murakami et al. 1987) able to oxidise ethoxycoumarin. Rat reductase was successively used to build up chimeras with bovine (CYP17A1), dog (CYP2B11) and human (CYP3A4, CYP1A2) P450s (Shet et al. 1994, Fisher et al. 1992).

A general approach called the "Molecular Lego" (Sadeghi et al. 2001, Gilardi et al. 2002) was then applied to P450 enzymes by fusing class II human P450s with the soluble reductase of Bacillus megaterium P450 BM3 (BMR), resulting in a soluble and self-sufficient system. Examples of such fusion systems are human CYP2E1 (Fairhead et al. 2005), CYP2C9, CYP2C19, CYP3A4 (Dodhia et al. 2006), CYP2A6, CYP2C6 and CYP4F11 (Ortolani 2012, Rua 2012) and monkey CYP2C20 and dog CYP2D15 (Rua et al., 2010). The advantages reported for these chimeras are the activity, solubility and correct folding in absence of detergents, and the simple addition of $\mathrm{NAD}(\mathrm{P}) \mathrm{H}$ and substrate to trigger catalytic activity. Moreover, in a further step $\mathrm{NAD}(\mathrm{P}) \mathrm{H}$ was replaced by electrode surface that provides the electrons driving the catalysis without the use of costly cofactors (Sadeghi et al. 2011).

Another example of artificial fusion systems is the CYP116B family. Nodate and colleagues (2006) have created a fusion protein with P450cam heme domain and the reductase domain of CYP116B2 (P450RhF). P450cam-RhFRed chimera shows 100\% conversion of camphor to 5-exohydroxycamphor and its specific recognition of substrates could be significantly enlarged by mutations in the different sites (Fowler et al. 2002). This chimera with Tyr96Phe mutation, combined with Tyr96Phe/Val247Ala mutations, has been studied with a high-throughput screening protocol by Robin et al. (2011), and was aimed at reaching the oxidation of useful molecules with an industrial application, such as terpenes $\alpha$ - and $\beta$-ionone relevant to the fragrance industry.

\section{APPLICATIONS OF P450s IN INDUSTRY: PERSPECTIVES}

The use of enzymes in industrial processes is a fast growing field that now is even more close to its maturity. Despite being attractive targets for catalysis, their wide application in industry still presents serious challenging due to a number of reasons. On one hand, biochemistry has made major advances in understanding their mechanisms, in controlling their proficiency and in 
producing high levels thanks to DNA recombinant methods and heterologous expression technologies (Roiban and Reetz 2015).

Protein engineering both by rational mutagenesis methods and in vitro darwinian evolution strategies has offered a handle in improving their stability to temperature and $\mathrm{pH}$, their resistance in organic solvent environments, their immobilisation on suitable supports. Moreover the growing legislative attention to the environment and demand for sustainable approaches to chemical synthesis has highlighted the intrinsic advantages in the use of enzymes as catalysts. In spite of their remaining limitations of possibly higher costs, more and more areas of applications have been uptaken in industry (Choi et al. 2015)

The application of P450s in industry is mainly in the area of generation of drug metabolites and synthetic intermediates as they can produce fine chemicals at high grade of purity. Heterologous expression in Escherichia coli or insect cells allows to obtain recombinant enzymes that can be used to produce molecules for use in the pharmaceutical industry. The cofactor regeneration and the costs associated with it, as well as narrow substrate specificity, the limited solvent tolerance are some of limitations encountered in the use of P450s on industrial processes (O'Reilly et al. 2011, Urlacher and Girhard 2012). In some case a whole-cell approach has given the best solution for specific problems. In 2003 Aventis-Pharma and the CNRS (Gif sur Yvette, France) have demonstrated the feasibility of transferring a complex biosynthetic pathway from higher eukaryotes into microorganisms producing hydrocortisone in yeast (Szczebara et al. 2003). Here complex products have been synthetized, replacing long and expensive synthetic multi-step reactions. In 2006, P450 BM3 was implemented in the preparation of metabolites of propanolol (Otey et al. 2006). The high catalytic activity of this enzyme is very attractive, and thus the random mutagenesis approach has been largely used in order to expand the range of the wild-type (WT) protein to include different substrates and create a new product. Many different high throughput screening methods have been proposed for discovering favourable random mutations in BM3 mutants evolved to recognise specific substrates. One of such methods is represented by the alkali $\mathrm{NAD}(\mathrm{P}) \mathrm{H}$ assay that has allowed to identify mutants capable of specific reactions within a library of random mutants generated by error prone PCR (Gilardi et al. 2002, Di Nardo and Gilardi 2012). Rational mutagenesis studies on Trp96 conserved residue, shows a primary role in the heme coordination through some key hydrogen bonds (Munro et al. 1994 and Ravichandran et al. 1993). Substitution of Phe87 makes BM3 able to hydroxylate lauric and myristic acid, mainly at the $\omega$ position, that is not reached by the WT enzyme. Phe87Val combined with Ala82Phe mutation resulted in an increase in the active site space, allowing more substrate hydroxylation, while other 
mutants (Cha et al. 2014) can make metabolites of non-steroidal anti-inflammatory drug diclofenac (mimic 4'- and 5'- P450s human metabolites).

Other interesting examples of the utility of BM3 regard the conversion of terpene to perillyl alcohol or the 1hexane to 1,2-epoxy hexane.
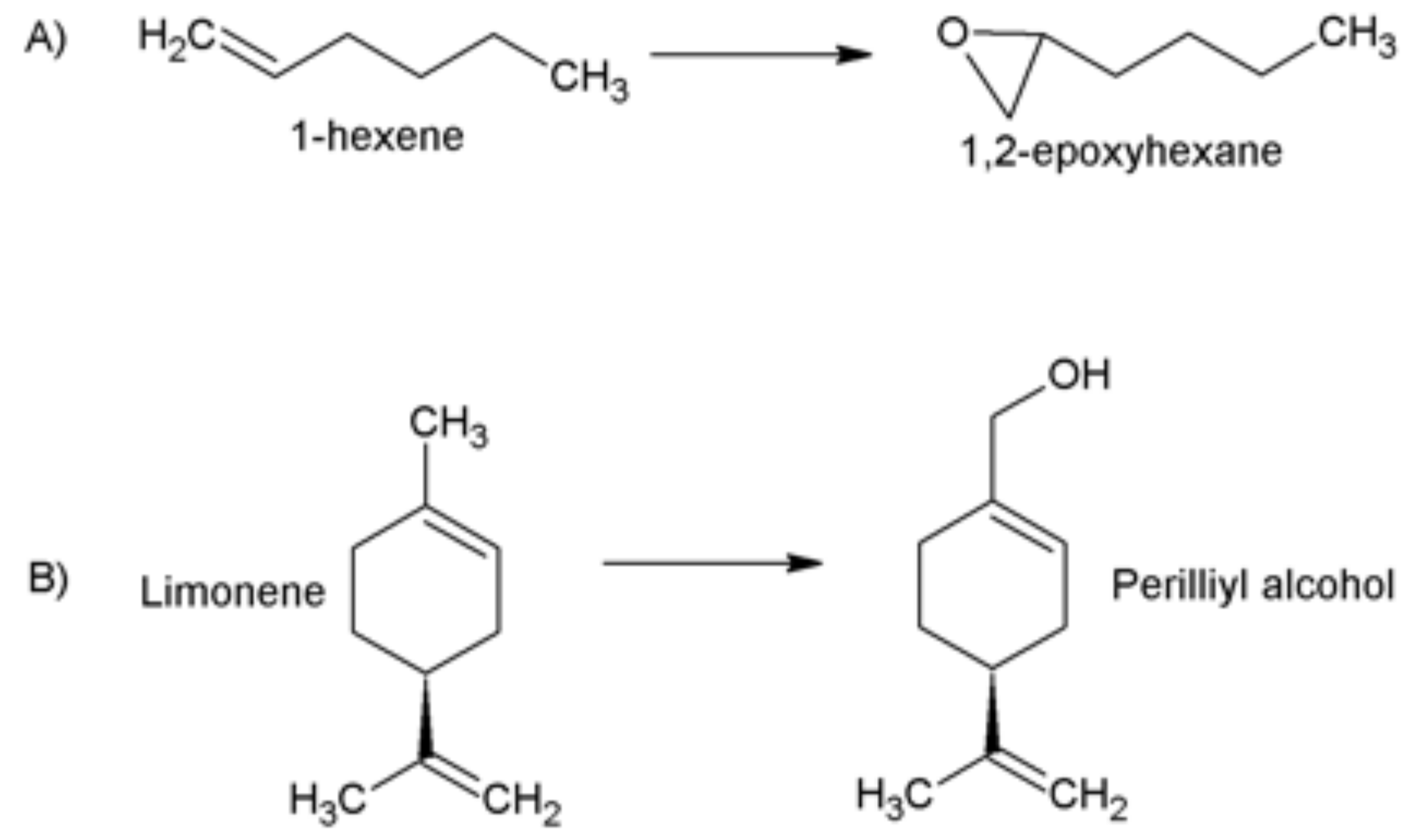

C)
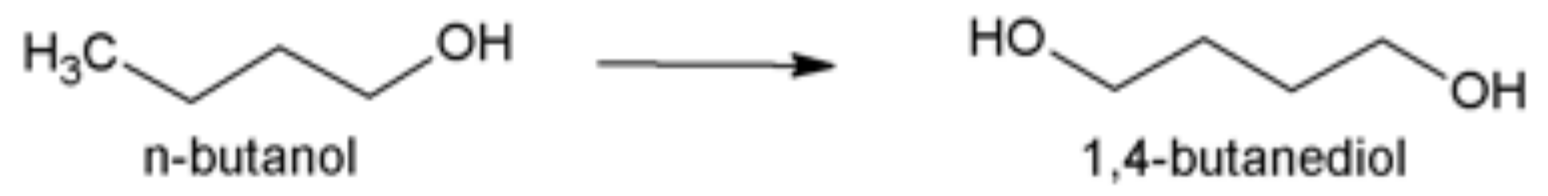

FIGURE 5. A) 1-hexene is converted to 1,2 epoxyhexane by BM3 triple mutants produced by saturation mutagenesis of the active site (Kubo 2006). B) Reaction performed by Ala264Val/Ala238Val/Lys437Phe BM3 triple mutant (Seifert 2011) C) I83M/I82T mutant of P450pyr catalysed reaction: hydroxylation of nbutanol 1 to 1,4-butanediol.

The huge protein engineering approach on BM3 is a versatile target able to perform different reactions useful in several fields. 
However, using the chimera approach, interesting results have been obtained with CYP105D7, that is a class I type of CYP, that requires electrons provided through separated electron transfer proteins (ferredoxin and ferredoxin reductase) for the hydroxylation of 7-hydroxy-3-(4-hydroxyphenyl) chromen-4-one (Daidzein) an isoflavones.

Joining the reductase partners and the CYP heme domain, the fusion enzyme obtained by Choi et al. (2012) catalyses hydroxylation of daidzein more efficiently, with a $\mathrm{k}_{\mathrm{cat}} / \mathrm{K}_{\mathrm{M}}$ value of $16.8 \mu \mathrm{M}^{-1} \mathrm{~min}^{-1}$ and with very high regio-selectivity.

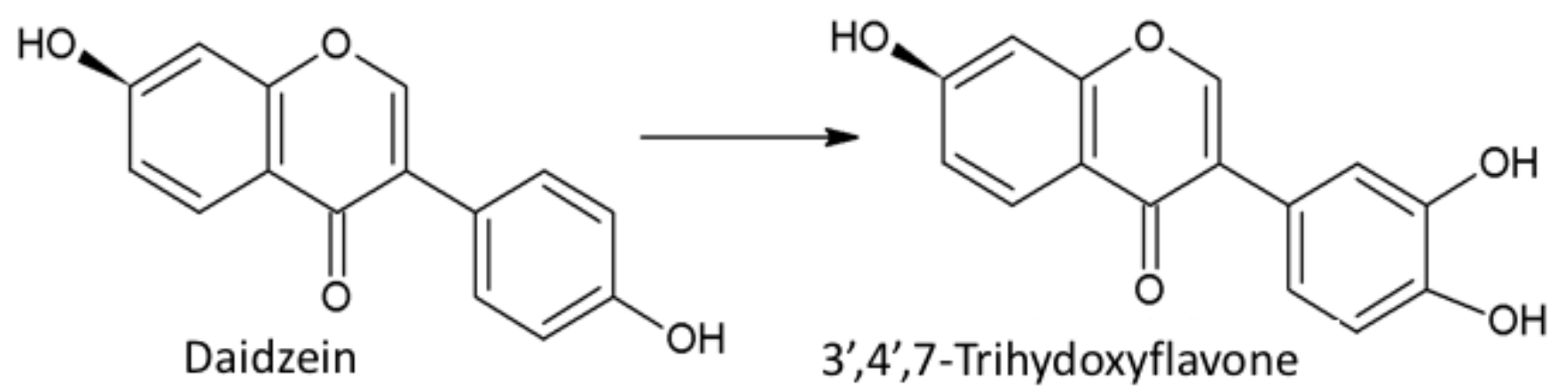

FIGURE 6. The reaction catalised by 3'-ASDH. This fusion artificial enzyme hydroxylates the 3' of the daidzein B-ring (Choi 2012).

Terminal hydroxylation of n-butanol to 1,4-butanediol, a useful reaction for industrial purposes (Barikani et al. 2009), have been reached with directed evolution, creating Iso83Met/Iso82Thr, a mutant of P450pyr monooxygenase (Yang et al. 2014) that represents a green route alternative to the synthetic traditional route for obtaining this product. This approach is fundamental in order to convert a hydrophilic compound that was not accepted by the class I wild-type enzyme.

Another field of application for P450s is the production of hydroxy-fatty acids. The enzymatic oxidation catalysed by P450s on non-activated carbon is a great advantage in different industrial processes. They are widely used in different industrial fields, such as the chemical, food, cosmetic and biofuel industries. Hydroxy-fatty acids are often used as starting materials for the synthesis of resins, polymers, biopolymers, and there is evidence that these polymers, synthesized from hydroxy fatty acids, are much more resistant and flexible than petroleum-derived ones (Burdock et al. 2006). 10- and 12-hydroxystearic acid is used in the manufacturing of lubricants, ricinoleic acid in soaps and also in the textile industry (Mutlu and Meier 2010). Due to the hydroxylation, fatty acids are more stable, more reactive and more solvent miscible, in comparison to non-hydroxylated fatty acids (Metzger and Bornscheuer 2006).

Another interesting P450 from Bacillus megaterium, with potential biotechnological application, is CYP106A2, a NADPH dependent protein composed of a FMN domain (megaredoxin reductase) and an iron- 
sulphur protein (megaredoxin). It is able to hydroxylate various 3-oxo-D4-steroids, mainly at the $15 \beta-$ position. These hydroxylated products are very important in the pharmaceutical industry, and they are precursors in the synthesis of several steroids compounds. Moreover, Bleif and co-workers have also reported its ability to perform one-step regioselective reaction of the anti-inflammatory pentacyclic triterpene 11-keto- $\beta$-boswellic acid (KBA), and to our knowledge this is the first reported pentacyclic triterpene conversion performed by a prokaryotic $\mathrm{P} 450$. They have also reported a whole-cell system using Bacillus megaterium strain MS941 for the conversion of KBA, with a 15-fold increase in comparison with the naturally CYP106A2 expressing Bacillus megaterium strain (ATCC 13368).

\section{CONCLUSIONS}

The flexibility of P450 enzymes in the recognition of different substrates, the possibility of generating or detecting industrial relevant metabolites, as well as the use of these enzymes in environmental detoxification, are the main reasons that have made these enzymes mature as useful biocatalysts. Every year more new enzymes are discovered from different kingdoms of life, lately even from viruses (Nelson 2009). An intense study of their electron transfer chain, especially for self-sufficient enzymes that display the highest efficiency in catalysis, important in biotechnological applications. Also relevant is the design of new, artificial, selfsufficient enzymes, that overcome possible limitations of the P450 catalytic unit. Biotechnological applications, involving P450 monooxygenases, are nowadays becoming more of a reality, but further work should be focused on key aspects, such as improving the stability of the P450s and cofactor regeneration during biocatalysis. The development of efficient and self-sufficient P450s opens up new horizons in the field of the synthesis of new molecules, pro-drug activation, bioremediation and whole-cell applications.

\section{ACKNOWLEDGEMENTS}

A.C. acknowledges support from the Compagnia di San Paolo for participation to the

Conference "Concepts in catalysis: from heterogeneous to homogeneous and enzymatic catalysis" held at Accademia dei Lincei in Rome on February 25-26 , 2016.

\section{REFERENCES}

Astuti Y, Topoglidis E, Gilardi G, Durrant JR (2004) Cyclic voltammetry and voltabsorptometry studies of redox proteins immobilised on nanocrystalline tin dioxide electrodes. Bioelectrochemistry 63: 55-59.

Barikani M, Honarkar H, and Barikani M (2009) Synthesis and Characterization of Polyurethane Elastomers Based on Chitosan and Poly(epsilon-caprolactone). J Appl Polym Sci 112:3157-3165. 
Burdock GA, Carabin IG and Griffiths JC (2006) Toxicology and pharmacology of sodium ricinoleate. Food Chem Toxicol 44:1689-1698.

Cha GS, Ryu SH, Ahn T and Yun CH (2014) Regioselective hydroxylation of 17 beta-estradiol by mutants of CYP102A1 from Bacillus megaterium. Biotechnol Lett 36:2501-2506.

Choi JM, Han SS, Kim Kim (2015) Industrial applications of enzyme biocatalysis: Current status and future aspects. Biotechnol Adv 33:1443-1454.

Choi KY, Jung E, Jung DH, An BR, Pandey BP, Yun H, Sung C, et al. (2012) Engineering of daidzein 3 'hydroxylase P450 enzyme into catalytically self-sufficient cytochrome P450. Microb Cell Fact 11:81.

Choi KY, Jung E, Jung DH, An BR, Pandey BP, Yun H, Park HY, Kazlauskas RJ, Kim BG (2012) Cloning, expression and characterization of CYP102D1, a self-sufficient P450 monooxygenase from Streptomyces avermitilis. FEBS J 279:1650-62.

Chowdhary PK, Alemseghed M, and Haines DC (2007) Cloning, expression and characterization of a fast selfsufficient P450: CYP102A5 from Bacillus cereus. Arch Biochem Biophys 468(1):32-43.

Daiber A, Nauser, T, Takaya N, Kudo T, Weber P, Hultschig C, Shoun H. and Ullrich V (2002) Isotope effects and intermediates in the reduction of NO by P450NOR. J Inorg Biochem 88:343-352.

Daiber A, Shoun H and Ullrich V (2005) Nitric oxide reductase (P450nor) from Fusarium oxysporum. J Inorg Biochem 99:185-193.

De Mot R, and Parret AHA (2002) A novel class of self-sufficient cytochrome P450 monooxygenases in prokaryotes. Trends Microbiol 10:502-508.

Di Nardo G and Gilardi G (2012) Optimization of the Bacterial Cytochrome P450 BM3 System for the Production of Human Drug Metabolites. Int J Mol Sci 13:15901-15924.

Di Nardo G, Dell'Angelo V, Catucci G, Sadeghi SJ and Gilardi G (2016) Subtle structural changes in the Asp251Gly/Gln307His P450 BM3 mutant responsible for new activity toward diclofenac, tolbutamide and 
ibuprofen. Arch Biochem Biophys 602:106-115.

Dietrich M, Eiben, S, Asta C, Do TA, Pleiss J and Urlacher VB (2008) Cloning, expression and characterisation of CYP102A7, a self-sufficient P450 monooxygenase from Bacillus licheniformis. Appl Microbiol Biot 79:931-940.

Dodhia VR, Fantuzzi A and Gilardi G (2006) Engineering human cytochrome P450 enzymes into catalytically self-sufficient chimeras using molecular lego. J Biol Inorg Chem 11:903-916.

Durairaj P, Jung E, Park HH, Kim BG, Yun H (2015) Comparative functional characterization of a novel benzoate hydroxylase cytochrome P450 of Fusarium oxysporum. Enzym Microb Tech 70:58-65.

Fairhead M, Giannini S, Gillam EMJ and Gilardi G (2005) Functional characterisation of an engineered multidomain human P450 2E1 by molecular Lego. J Biol Inorg Chem 10:842-853.

Fisher CW, Shet MS, Caudle DL, Martinwixtrom CA and Estabrook RW (1992) High-level expression in Escherichia coli of enzymatically active fusion proteins containing the domains of mammalian cytochromes-P450 and nadph-P450 reductase flavoprotein. P Natl Acad Sci USA 89:10817-10821.

Fowler SM, Taylor JM, Friedberg T, Wolf CR and Riley RJ (2002) CYP3A4 active site volume modification by mutagenesis of leucine 211. Drug Metab Dispos 30:452-456.

Froehlich JE, Itoh A, Howe GA (2001) Tomato allene oxide synthase and fatty acid hydroperoxide lyase, two cytochrome P450s involved in oxylipin metabolism, are targeted to different membranes of chloroplast envelope. Plant Physiol 125:306-31.

Garfinkel D (1958) Studies on pig liver microsomes. I. Enzymic and pigment composition of different microsomal fractions. Arch Biochem Biophys 77:493-509.

Garny S, Verschoor J, Gardiner N, Jordaan J (2014) Spectrophotometric activity microassay for pure and recombinant cytochrome P450-type nitric oxide reductase. Anal Biochem 447:23-29.

Garny S, Beeton-Kempen N, Gerber I, Verschoor J and Jordaan J (2016) The co-immobilization of P450-type nitric oxide reductase and glucose dehydrogenase for the continuous reduction of nitric oxide via cofactor recycling. Enzym Microb Tech 85:71-81. 
Gilardi G, Meharenna YT, Tsotsou GE, Sadeghi SJ, Fairhead M and Giannini S (2002) Molecular Lego: design of molecular assemblies of P450 enzymes for nanobiotechnology. Biosens Bioelectron 17:133-145.

Gilardi G and Di Nardo G (2016) Heme iron centers in cytochrome P450: structure and catalytic activity. Rend Lincei Sci-Fis in press.

Gotoh O (1992) Substrate recognition sites in cytochrome-p450 family-2 (cyp2) proteins inferred from comparative analyses of amino-acid and coding nucleotide-sequences. J Biol Chem 267:83-90.

Grechkin AN, Hamberg M (1996) Divinyl ether synthase from garlic (Allium sativum L.) bulbs: sub-cellular localization and substrate regio-and stereospecificity. FEBS Lett 388:112-4.

Guengerich FP and Munro AW (2013) Unusual Cytochrome P450 Enzymes and Reactions. J Biol Chem 288:1706517073.

Gustafsson MCU, Roitel O, Marshall KR, Noble MA, Chapman SK, Pessegueiro A, Fulco AJ, et al. (2004) Expression, purification, and characterization of Bacillus subtilis cytochromes P450CYP102A2 and CYP102A3: Flavocytochrome homologues of P450BM3 from Bacillus megaterium. Biochemistry 43:5474-5487.

Hannemann F, Bichet A, Ewen KM and Bernhardt R (2007) Cytochrome P450 systems - biological variations of electron transport chains. BBA-Gen Subjects 1770:330-344.

Hou QC, Ufer GD and Bartels D (2016) Lipid signalling in plant responses to abiotic stress. Plant Cell Environ 39:1029-1048.

Isin EM and Guengerich FP (2007) Complex reactions catalyzed by cytochrome P450 enzymes. BBA- Gen Subjects 1770: 314-329.

Itoh A, Howe GA (2001) Molecular cloning of a divinyl ether synthase. Identification as a CYP74 cytochrome P-450. J Biol Chem 276: 3620-3627.

Kitazume T, Takaya N, Nakayama N, Shoun H (2000) Fusarium oxysporum fatty-acid subterminal hydroxylase is a membrane-bound eukaryotic counterpart of Bacillus megaterium cytochrome P450BM3. J 
Biol Chem 275:734-740.

Kitazume T, Tanaka A, Takaya N, Nakamura A, Matsuyama S, Suzuki T, Shoun H (2002) Kinetic analysis of hydroxylation of saturated fatty acids by recombinant P450foxy produced by an Escherichia coli expression system. Eur J Biochem 269:2075-2082.

Kitazume T, Yamazaki Y, Matsuyama S, Shoun H and Takaya N (2008) Production of hydroxy-fatty acid derivatives from waste oil by Escherichia coli cells producing fungal cytochrome P450foxy. Appl Microbiol Biot 79:981-988.

Kudo T, Tomura, D, Liu DL, Dai XQ and Shoun, H (1996) Two isozymes of P450nor of Cylindrocarpon tonkinense: Molecular cloning of the cDNAs and genes, expressions in the yeast, and the putative NAD(P)H-binding site. Biochimie 78:792-799.

Lau SMC, Harder PA and Okeefe, DP (1993) Low-carbon monoxide affinity allene oxide synthase is the predominant cytochrome-p450 in many plant-tissues. Biochemistry 32(8):1945-1950.

Liu L, Schmid RD and Urlacher V (2006) Cloning, expression, and characterization of a self-sufficient cytochrome P450 monooxygenase from Rhodococcus ruber DSM 44319. Appl Microbiol Biot 72:876-882.

Metzger JO and Bornscheuer U (2006) Lipids as renewable resources: current state of chemical and biotechnological conversion and diversification. Appl Microbiol Biot 71:13-22.

Minerdi D, Sadeghi SJ, Di Nardo G, Rua F, Castrignano S, Allegra P and Gilardi G (2015) CYP116B5: a new class VII catalytically self-sufficient cytochrome P450 from Acinetobacter radioresistens that enables growth on alkanes. Mol Microbiol 95:539-554.

Miura Y, Fulco AJ (1974) (Omega -2) hydroxylation of fatty acids by a soluble system from Bacillus megaterium. J Biol Chem 249:1880-8.

Munday SD, Maddigan NK, Young RJ and Bell SG (2016) Characterisation of two self-sufficient CYP102 family monooxygenases from Ktedonobacter racemifer DSM44963 which have new fatty acid alcohol product profiles. BBA-Gen Subjects 1860: 1149-1162

Munro AW, Malarkey K, McKnight J, Thomson AJ, Kelly SM, Price, NC, Lindsay JG, et al., (1994) the role of 
tryptophan-97 of cytochrome-p450-bm3 from Bacillus Megaterium in catalytic function, evidence against the covalent-switching hypothesis of p-450 electron-transfer. Biochem J 303:423-428.

Munro AW, Leys DG, McLean KJ, Marshall KR, Ost TWB, Daff S, Miles CS, et al. (2002) P450BM3: the very model of a modern flavocytochrome. Trends Biochem Sci 27:250-257.

Murakami H, Yabusaki Y, Sakaki T, Shibata M and Ohkawa H (1987) A genetically engineered p450 monooxygenase - construction of the functional fused enzyme between rat cytochrome-p450c and nadphcytochrome-p450 reductase. DNA-J Molec Cell Bio 6:189-197.

Mur LA, Carver TL, Prats E (2006) NO way to live; the various roles of nitric oxide in plant-pathogen interactions. J Exp Bot 57:489-505.

Mutlu H and Meier MAR (2010) Castor oil as a renewable resource for the chemical industry. Eur J Lipid Sci Technol 112:10-30.

Nakahara K, Tanimoto T, Hatano K, Usuda K, Shoun H (1993) Cytochrome P-45055A1 (P-450dNIR) acts as nitric oxide reductase employing NADH as thedirect electron donor. J Biol Chem 268: 8350-8355.

Nakayama N, Takemae A, Shoun H (1996) Cytochrome P450foxy, a catalytically self-sufficient fatty acid hydroxylase of the fungus Fusarium oxysporum. J Bio Chem (Tokyo) 119:435-440.

Nelson DR (2009) The Cytochrome P450 Homepage. Human Genomics 4:59-65.

Nodate M, Kubota M and Misawa N (2006) Functional expression system for cytochrome P450 genes using the reductase domain of self-sufficient P450RhF from Rhodococcus sp NCIMB 9784. Appl Microbiol Biot 71:455-462.

Omura T, Sato RJ (1964) The carbon monoxide-binding pig- ment of liver microsomes. J Biol Chem 239:23702378.

O'Reilly E, Koehler V, Flitsch SL and Turner NJ (2011) Cytochromes P450 as useful biocatalysts: addressing the limitations. Chem Comm 47(9):2490-2501. 
Ortiz de Montellano PR (2015) Cytochrome P450. Structure, Mechanism, and Biochemistry. Springer, New York.

Ortolani A (2012) Engineering CYP2C8 and CYP2A6 for drug screening. Dissertation, University of Turin, Italy.

Oshima R, Fushinobu S, Su F, Zhang L, Takaya N, Shoun H (2004) Structural evidence for direct hydride transfer from NADH to cytochrome P450nor. J Mol Biol 342:207-217.

Otey CR, Bandara G, Lalonde J, Takahashi K and Arnold FH (2006) Preparation of human metabolites of propranolol using laboratory-evolved bacterial cytochromes P450. Biotechnol Bioeng 93:494-499.

Poulos TM, Barry CF and Andrew JH (1987) High-resolution crystal structure of Cytochrome P450cam. J Mol Biol 165:687-700.

Proctor RH, Brown DW, Plattner RD, and Desjardins AE (2003) Co-expression of fifteen contiguous genes delineates a fumonisin biosynthetic gene cluster in Gibberella moniliformis. Fungal Genet Biol 38:237-249.

Psylinakis E, Davoras EM, Ioannidis N, Trikeriotis M, Petrouleas V, Ghanotakis DF (2001) Isolation and spectroscopic characterization of a recombinant bell pepper hydroperoxide lyase. BBA-Mol Cell Biol L 1533:2119-127.

Ravichandran KG, Boddupalli SS, Hasemann CA, Peterson JA and Deisenhofer J (1993) Crystal-structure of hemoprotein domain of $\mathrm{p} 450 \mathrm{bm}-3$, a prototype for microsomal p450s. Science 261:731-736.

Roberts GA, Celik, A, Hunter DJB, Ost TWB, White JH, Chapman SK, Turner NJ et al. (2003) A self-sufficient cytochrome $\mathrm{P} 450$ with a primary structural organization that includes a flavin domain and a $2 \mathrm{Fe}-2 \mathrm{~S}$ redox center. $\mathrm{J}$ Biol Chem 278:48914-48920.

Robin A, Koehler V, Jones A, Ali A, Kelly PP, O'Reilly E, Turner NJ, et al. (2011) Chimeric self-sufficient P450cam-RhFRed biocatalysts with broad substrate scope. J Org Chem 7:1494-1498.

Roiban GD and Reetz MT (2015) Expanding the toolbox of organic chemists: directed evolution of P450 monooxygenases as catalysts in regio- and stereoselective oxidative hydroxylation. Chem Comm 51:2208-2224. 
Rua F, Sadeghi SJ, Di Nardo G and Gilardi G (2010) Alternative to animal testing for new drugs: structural, functional and electrochemical studies of monkey CYP2C20 and dog CYP2D15. FEBS J 277:280-280.

Rua F (2012) Engineering platforms for drug metabolism as alternative to P450 testing in animals. Dissertation. University of Turin, Italy.

Sadeghi SJ, Tsotsou GE, Fairhead M, Meharenna YT and Gilardi G (2001). Rational design of P450 enzymes for biotechnology. Focus Biotechnol:71-104.

Sadeghi SJ, Fantuzzi A and Gilardi G (2011) Breakthrough in P450 bioelectrochemistry and future perspectives. BBA-Proteins Proteom 1814:237-248.

Sadeghi, SJ and Gilardi, G (2013) Chimeric P450 enzymes: Activity of artificial redox fusions driven by different reductases for biotechnological applications. Biotechnol Appl Bioc 60:102-110.

Schmitz D, Zapp J and Bernhardt R (2012) Hydroxylation of the triterpenoid dipterocarpol with CYP106A2 from Bacillus megaterium. FEBS J 279:1663-1674.

Seifert A, Antonovici M, Hauer B, Pleiss J (2011) An efficient route to selective bio-oxidation catalysts: an iterative approach comprising modeling, diversification, and screening, based on CYP102A1. Chembiochem 12:1346-51.

Seo JA, Proctor RH, Plattner RD (2001) Characterization of four clustered and coregulated genes associated with fumonisin biosynthesis in Fusarium verticillioides. Fungal Genet Biol 34:155-165.

Sevrioukova IF, Li H, Zhang H, Peterson JA, Poulos TL (1999) Structure of a cytochrome P450-redox partner electron-transfer complex. Proc Natl Acad Sci USA 96:1863-8.

Shet MS, Fisher CW, Arlotto MP, Shackleton CHL, Holmans PL, Martinwixtrom CA, Saeki Y, et al. (1994) Purification and enzymatic-properties of a recombinant fusion protein expressed in Escherichia-coli containing the domains of bovine p450 17a and rat nadph-p450 reductase. Arch Biochem Biophys 311:402-417.

Shibata Y, Matsui K, Kajiwara T, Hatanaka A (1995) Fatty acid hydroperoxide lyase is a heme protein. Biochem Bioph Res Co 207:438-443.

Shoun H, Sudo Y, Seto Y, Beppu T (1983) Purification and properties of a cytochrome P-450 of a fungus, Fusarium oxysporum. J Biochem 94:1219-1229. 
Shoun H, Fushinobu S, Jiang L, Kim SW, Wakagi T (2012) Fungal denitrification and nitric oxide reductase cytochrome P450nor. Philos Trans R Soc Lond B Biol Sci 637:1186-1194.

Sideri A, Goyal A, Di Nardo G, Tsotsou GE and Gilardi G (2013) Hydroxylation of non-substituted polycyclic aromatic hydrocarbons by cytochrome P450 BM3 engineered by directed evolution. J Inorg Chem 120:1-7.

Stundl UM, Schmidt I, Scheller US Chrnid R, Schunck WH and Schauer F (1998) Purification and characterization of cytosolic cytochrome P450 forms from yeasts belonging to the genus Trichosporon. Arch Biochem Biophys 357:131-136.

Su F, Fushinobu S, Takaya N, Shoun H (2004) Involvement of a Glu71-Arg64 couple in the access channel for NADH in cytochrome p450nor. Biosci Biotech Bioch 68:1156-1159.

Sydenham EW, Gelderblom WCA, Thiel PG, Marasas WF (1990) Evidence for the natural occurrence of fumonisin B1, a mycotoxin produced by Fusarium moniliforme, in corn. J Agric Food Chem 38:285-290.

Szczebara FM, Chandelier C, Villeret C, Masurel A, Bourot, S, Duport C, Blanchard S, et al. (2003) Total biosynthesis of hydrocortisone from a simple carbon source in yeast. Nature Biotechnol 21:143-149.

Takaya N and Shoun H (2000) Nitric oxide reduction, the last step in denitrification by Fusarium oxysporum, is obligatorily mediated by cytochrome P450nor. Mol Gen Genet 263:342-348.

Toritsuka N, Shoun H, Singh UP, Park SY, Lizuka T and Shiro Y (1997) Functional and structural comparison of nitric oxide reductases from denitrifying fungi Cylindrocarpon tonkinense and Fusarium oxysporum. Biochim Biophys Acta 1338: 93-99.

Tsotsou GE, Cass AEG and Gilardi G (2002) High throughput assay for cytochrome P450BM3 for screening libraries of substrates and combinatorial mutants. Biosens Bioelectron 17:119-131.

Tsotsou GE, Sideri A, Goyal A, Di Nardo G and Gilardi G (2012) Identification of mutant Asp251Gly/Gln307His of cytochrome P450 BM3 for the generation of metabolites of diclofenac, ibuprofen and tolbutamide. Chem Eur J 18:3582-3588. 
Turpaev K, Bouton C, Drapier JC (2004) Nitric oxide-derived nitrosating species and gene expression in human monocytic cells. Biochemistry 43:10844-10850.

Umemura M, Su F, Takaya N, Shiro Y, Shoun H (2004) D88A mutant of cytochrome P450nor provides kinetic evidence for direct complex formation with electron donor NADH. Eur J Biochem 271:2887-2894.

Urlacher VB and Girhard M (2012) Cytochrome P450 monooxygenases: an update on perspectives for synthetic application. Trends Biotechnol 30:26-36.

Usuda K, Toritsuka N, Matsuo Y, Kim DH and Shoun H (1995) Denitrification by the fungus Cylindrocarpon tonkinense: anaerobic cell growth and two isozyme forms of cytochrome P-450nor. Appl Environ Microbiol 61: 883-889.

Valetti F and Gilardi G (2004) Directed evolution of enzymes for product chemistry. Nat Prod Rep 21:490-511.

Vick BA and Zimmerman DC (1984) Biosynthesis of Jasmonic Acid by Several Plant Species. Plant Physiol 75: 458-461.

Warman AJ, Robinson JW, Luciakova D, Lawrence AD, Marshall KR, Warren MJ, Cheesman MR, et al. (2012) Characterization of Cupriavidus metallidurans CYP116B1-A thiocarbamate herbicide oxygenating P450-phthalate dioxygenase reductase fusion protein. FEBS J 279:1675-1693.

Whitehouse CJC, Bell SG and Wong L (2012) P450(BM3) (CYP102A1): connecting the dots. Chem Soc Rev 41:1218-1260

Yang Y, Chi YT, Toh HH and Li Z (2015) Evolving P450pyr monooxygenase for highly regioselective terminal hydroxylation of n-butanol to 1,4-butanediol. Chem Comm 51:914-917.

Yin YC, Yu HL, Luan ZJ, Li RJ, Ouyang PF, Liu J and Xu JH (2014) Unusually Broad Substrate Profile of SelfSufficient Cytochrome P450 Monooxygenase CYP116B4 from Labrenzia aggregate. Chembiochem 15:2443-2449.

Zhang L, Takaya N, Kitazume T, Kondo T and Shoun H (2001) Purification and cDNA cloning of nitric oxide reductase cytochrome P450nor (CYP55A4) from Trichosporon cutaneum. Eur J Biochem 268:3198-3204. 